\title{
3D MODEL STUDIES ON THE EFFECT OF BED AND POWDER TYPE UPON RADIAL STATIC PRESSURE AND POWDER DISTRIBUTION IN METALLURGICAL SHAFT FURNACES
}

\begin{abstract}
The flow of gases in metallurgical shaft furnaces has a decisive influence on the course and process efficiency. Radial changes in porosity of the bed cause uneven flow of gas along the radius of the reactor, which sometimes is deliberate and intentional. However, holdup of solid particles in descending packed beds of metallurgical shaft furnaces can lead to unintentional changes in porosity of the bed along the radial reactor. Unintentional changes in porosity often disrupt the flow of gas causing poor performance of the furnace. Such disruptions of flow may occur in the blast furnace due to high level of powder content in gas caused by large amount of coal dust/powder insufflated as fuel substitute. The paper describes the model test results of radial distribution of static pressure and powder hold up within metallurgical reactor. The measurements were carried out with the use of 3D physical model of two-phase flow gas-powder in the moving (descending) packed bed. Sinter or blast furnace pellets were used as packed bed while carbon powder or iron powder were used as the powder. Wide diversity within both static pressure distribution and powder distribution along the radius of the reactor were observed once the change in the type of powder occurred.
\end{abstract}

Keywords: blast furnace, system: descending packed bed - gas-powder, pressure, holdup powder

\section{Introduction}

The flow of gas with powder through packed bed is observed in numerous industrial processes such as filtration of flue gases $[1,2]$ or metals production in metallurgical shaft furnaces [3-5]. The processes of obtaining zinc and lead carried out in shaft furnaces, copper matte smelting as well as extraction of iron from iron ores: blast furnace process and the process of direct reduction of iron ores, are typical examples of such flows in metallurgy. Blast furnace is however the most complex example of metallurgical shaft furnaces.

Gas flow in blast furnaces is countercurrent to descending lump charge and has a decisive influence on the course and process efficiency. The general principle of aerodynamics in the flow of gas through blast furnace is its uniform flow at each cross-section and height of solid material zone. Flow uniformity ensures equal washing of all charge lumps, thus rapid exchange of heat (gas transfers heat to a charge) and mass (gas receives heat oxygen from iron oxides and other metal oxides). In solid material zone the gas flow is conditioned by grain composition and the way charge is arranged inside the throat. The more uniform grain composition, the bigger hydraulic diameters (void spaces between lumps of charge) and the better (easier) gas flow. This is not confirmed in practice though, since replacement of coke with powder results in accumulation of large amount of powder in gas which is caused by incomplete combustion of coal. Uneven holdup of powder in the bed conditions affect the directions in which the gas flows depends on its distance from the walls or the center of blast furnace. Radial changes in porosity of the bed which cause uneven flow of gas along the radius of the reactor might sometimes be a deliberate and intentional action of the blast furnace operators. However, holdup of solid particles in descending packed bed can lead to uncontrolled changes in bed porosity along the radius of the metallurgical reactor and in consequence to the deformation of the flow. The function of radial changes in bed porosity is the change of static pressure along the radius of the reactor i.e., the radial distribution of static pressure.

The aim of the research described in the paper was to investigate the mechanism of powder holdup in a packed bed of metallurgical shaft furnaces through evaluation of gas velocity impact, type of metallurgical bed as well as type of two most essential fractions of blast furnace powder (coal powder and iron powder) upon static pressure distribution and powder distribution as the function of the radius of metallurgical reactor. On account of the technologies of metallurgical processes and large size reactors, experimental investigations on the flow are difficult to be carried out at the operating metallurgical units. Therefore, physical and mathematical simulations, which help understand the occurring phenomena, are employed [6-9]. 


\section{Experimental installation and procedure}

Investigations which aimed to evaluation of the effect of gas velocity and type of metallurgical bed upon static pressure distribution were conducted with the application of a physical model. Since, as the literature says [8], (3D) volume models reflect the real conditions much better than (2D) flat models, (3D) physical model of two-phase flow gas-powder through descending packed bed (described in [10]) was used for completing the research.

Previously, 3D tests of radial distribution of static pressure were carried out in model systems glass bed-glass powder (A system) as well as blast furnace pellets-iron powder (B system). The research presented here, blast furnace sinter bed-coal powder (C system) as well as blast furnace pellets bed-coal powder (D system) was realized with the application of previously described procedure [10]. The investigations were performed at maximum and minimum apparent velocity (velocity referring to void cross-section of the reactor), at 4 levels of bed height. Minimum apparent velocity of gas was the velocity value in the point where powder transport into the test column was observed. Maximum apparent velocity of gas was determined by the volume of powder holdup in the bed which tends to zero. The carried out investigations took into consideration Reynold's and Froude's criteria which pointed at similarities of the conditions in the performed investigations and the conditions inside the shaft of blast furnace and the reduction shaft in Corex installation. Table 1 presents information about the operational conditions of blast furnace shaft and Corex reduction shaft.

TABLE 1

Research conditions

\begin{tabular}{|c|c|c|c|c|}
\hline \hline \multicolumn{2}{|c|}{} & $\begin{array}{c}\text { Measuring } \\
\text { system }\end{array}$ & $\begin{array}{c}\text { Blast } \\
\text { furnace } \\
\text { (shaft) }\end{array}$ & $\begin{array}{c}\text { COREX } \\
\text { (reduction } \\
\text { shaft) }\end{array}$ \\
\hline $\begin{array}{c}\text { Diameter of bed } \\
\text { pieces, } d_{z}\end{array}$ & $\mathrm{~m}$ & $0.014-0.016$ & $0.01-0.03$ & $0.015-0.025$ \\
\hline Gas density, $\rho_{g}$ & $\mathrm{~kg} / \mathrm{m}^{3}$ & 1.205 & $0.67-0.85$ & 0.96 \\
\hline Gas viscosity, $\mu_{g}$ & $\mathrm{~Pa} \times \mathrm{s}$ & $1.86 \times 10^{-5}$ & $\begin{array}{c}(3.98-4.25) \\
\times 10^{-5}\end{array}$ & $4.49 \times 10^{-5}$ \\
\hline $\begin{array}{c}\text { Gas apparent } \\
\text { velocity, } U_{g}\end{array}$ & $\mathrm{~m} / \mathrm{s}$ & $0.4-1.2$ & $1-2$ & 1 \\
\hline $\begin{array}{c}\text { Bed velocity, } U_{z} \\
\text { Reynolds' Number } \\
\text { Re }=\rho_{g} U_{g} d_{z} / \mu_{g}\end{array}$ & $\mathrm{~m} / \mathrm{s}$ & $0.45 \times 10^{-3}$ & $\begin{array}{c}(0.6- \\
1.0) \times 10^{-3}\end{array}$ & $0.6 \times 10^{-3}$ \\
\hline $\begin{array}{c}\text { Froude's Number } \\
\text { Fr }=U_{z} /\left(d_{z} \times g\right)^{1 / 2}\end{array}$ & - & $\begin{array}{c}362-1243 \\
(1.1-1.2) \\
\times 10^{-3}\end{array}$ & $\begin{array}{c}157-1281 \\
(1.1-3.2) \\
\times 10^{-3}\end{array}$ & $\begin{array}{c}(1.1-1.6) \\
\times 10^{-3}\end{array}$ \\
\hline
\end{tabular}

where: $g$ - gravitational acceleration, $\mathrm{m} / \mathrm{s}^{2}$

\section{Investigation results into radial distribution of static pressure}

Investigation results into radial distribution of static pressure ( $\mathrm{C}$ and $\mathrm{D}$ systems) are shown in figures 1-4. For better presentation of the effects of gas introduction into coal powder, the results are contrasted with those obtained while earlier model system (B system) was applied. Frequently used marks and their meanings are listed in Table 2.

The results obtained proved that all analyzed systems feature static pressure differentiations of gas at the level of Tuyere nozzles. It decreases together with the increase of the bed height. At minimum velocity of gas, static pressure differentiation is much more pronounced.

TABLE 2

List of frequently used marks

\begin{tabular}{|c|c|c|c|c|c|c|c|}
\hline $\begin{array}{c}\text { Max. } \\
U_{g}, \\
\text { m/s }\end{array}$ & \begin{tabular}{|c|} 
Min. \\
$U_{g}$, \\
m/s \\
\end{tabular} & $\begin{array}{c}d_{z}, \\
\mathbf{m}\end{array}$ & $\begin{array}{l}\varepsilon_{0} \\
-\end{array}$ & $\begin{array}{c}d_{p}, \\
\mathbf{m}\end{array}$ & $\Phi_{p}$ & $\begin{array}{c}G, \\
\mathrm{~kg} / \mathrm{m}^{2} \mathrm{~s}\end{array}$ & Notes \\
\hline$\bullet \bullet$ & $\begin{array}{l}0 \Delta \\
\square \diamond\end{array}$ & 0.014 & 0.49 & $\begin{array}{c}(100-140) \\
\times 10^{-3}\end{array}$ & 0.78 & 0.45 & $\begin{array}{c}\text { bed: blast } \\
\text { furnace sinter; } \\
\text { powder: coal } \\
\text { powder - C }\end{array}$ \\
\hline$\bullet \bullet$ & $\begin{array}{l}0 \Delta \\
\square \diamond\end{array}$ & 0.016 & 0.48 & $\begin{array}{c}(100-140) \\
\times 10^{-3}\end{array}$ & 0.78 & 0.45 & $\begin{array}{c}\text { bed: blast } \\
\text { furnace pellets; } \\
\text { powder: coal } \\
\text { powder - D }\end{array}$ \\
\hline
\end{tabular}

where: $d_{z}$ - diameter of bed pieces, $\varepsilon_{0}$ - void fraction in packed bed, $d_{p}$-diameter of powder particles, $\Phi_{p}$ - shape factor of the powder, $G$ - mass apparent velocity of the powder stream.

In case of $C$ and $D$ systems static pressure of the reactor is higher at the wall than inside the bed. At the highest level of the bed height and at maximum gas velocity, radial distribution of static pressure takes constant or almost constant value which is shown in figures 1-4.

\section{Computation results of radial distribution of powder}

Making use of experimentally obtained values of radial distribution of static pressure, radial distribution of volume fraction of total holdup of powder $\left(\varepsilon_{p}\right)$ in the packed bed at its lower level (0-100 mm) was calculated. Computations were performed for $\mathrm{C}$ and D systems with the application of the described in [11] mathematical model. Corrected correlation between additional drag coefficient induced by gravitation, collisions and friction of coal powder particles $(F k)$ and Froude number $(F r)$ was added to the model. The value of Fk coefficient for the model system - sinter bed or blast furnace pellets + coal powder (C and D systems) - is expressed by the following equation: $F k=30730 \mathrm{e}^{-35.91 \mathrm{Fr}}$. Figure 5 shows adjusted relation $F k=f(F r)$. Figure 6 shows radial distribution of $\varepsilon_{p}$, coefficients at the lower section (0-100 $\mathrm{mm}$ ) of a bed height in systems B, C and D.

Totally diverse distribution of coal powder and iron powder is possible to be observed. At the maximum velocity of gas coal concentration at the wall is more intensive than inside the reactor. At the minimum apparent velocity of gas, radial distribution of coal powder disappears whereas radial distribution of iron powder disappears at the maximum velocity. 


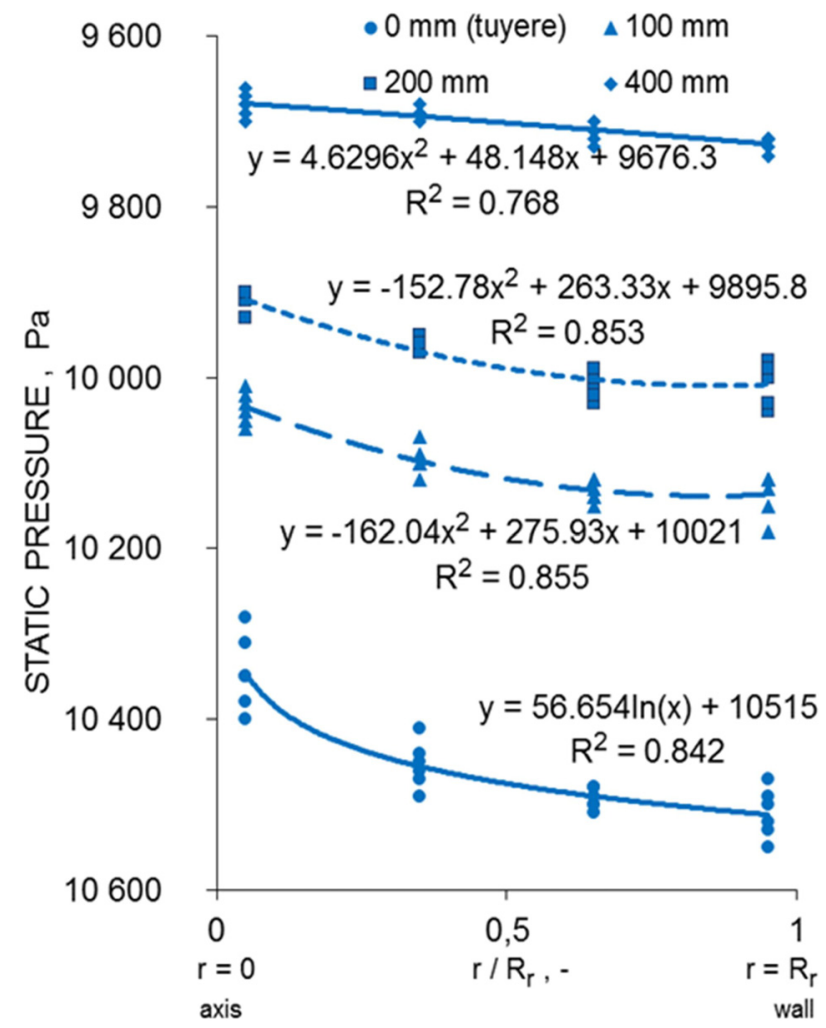

Fig. 1. Values of static pressure radial distribution (system C; $U_{g}=0.4 \mathrm{~m} / \mathrm{s}$ )

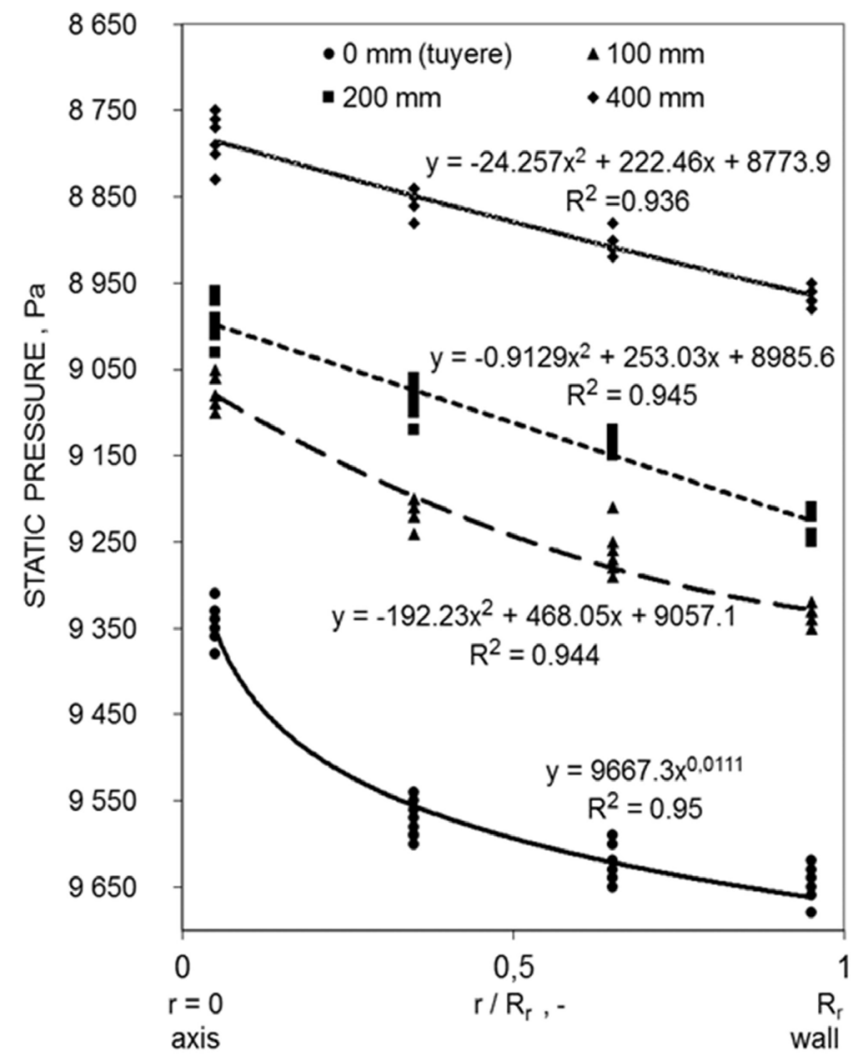

Fig. 3. Values of static pressure radial distribution (system D; $U_{g}=0.4 \mathrm{~m} / \mathrm{s}$ )

Totally diverse distribution of coal powder and iron powder is possible to be observed. At the maximum velocity of gas coal concentration at the wall is more intensive than inside the reac-

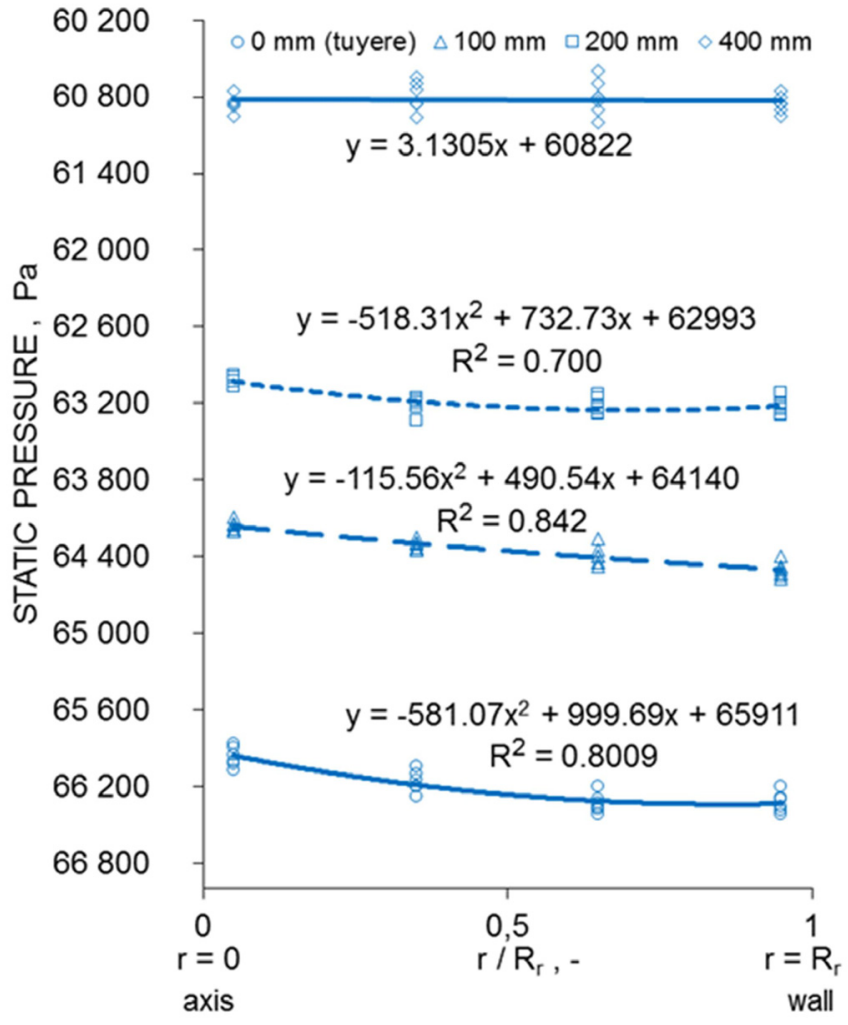

Fig. 2. Values of static pressure radial distribution (system C; $U_{g}=1.1 \mathrm{~m} / \mathrm{s}$ )

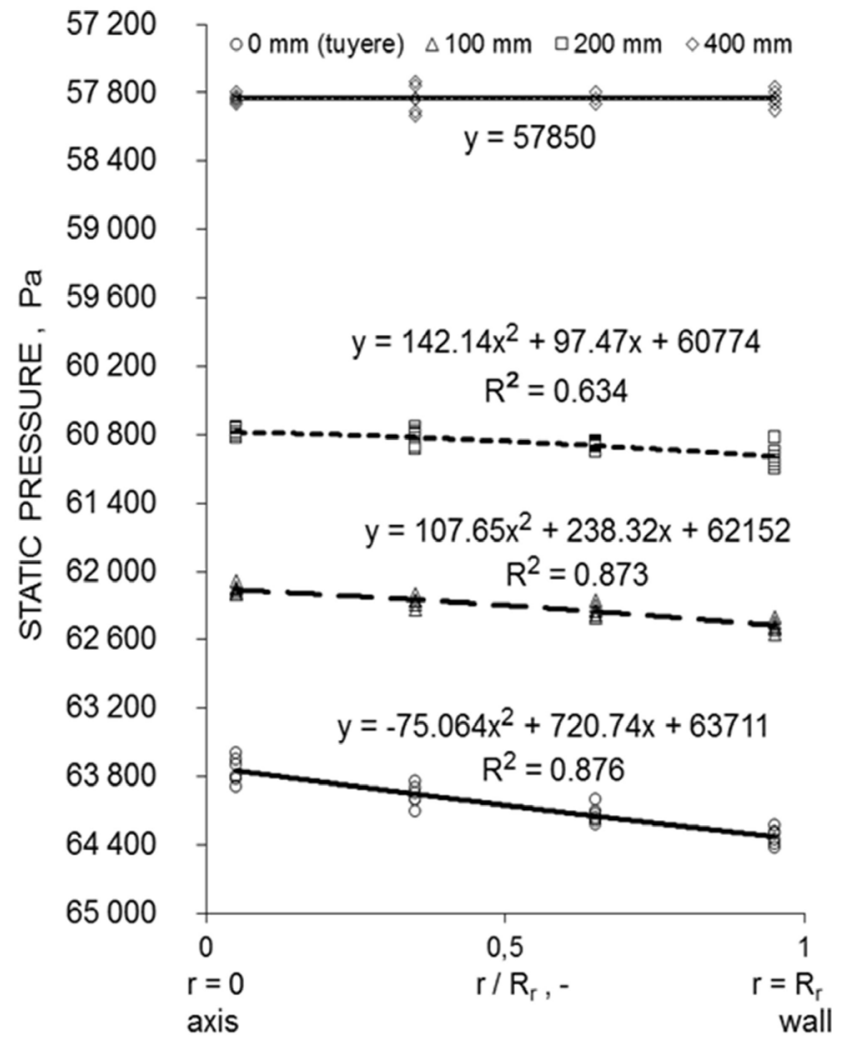

Fig. 4. Values of static pressure radial distribution (system $\mathrm{D} ; U_{g}=1.2 \mathrm{~m} / \mathrm{s}$ )

tor. At the minimum apparent velocity of gas, radial distribution of coal powder disappears whereas radial distribution of iron powder disappears at the maximum velocity. 


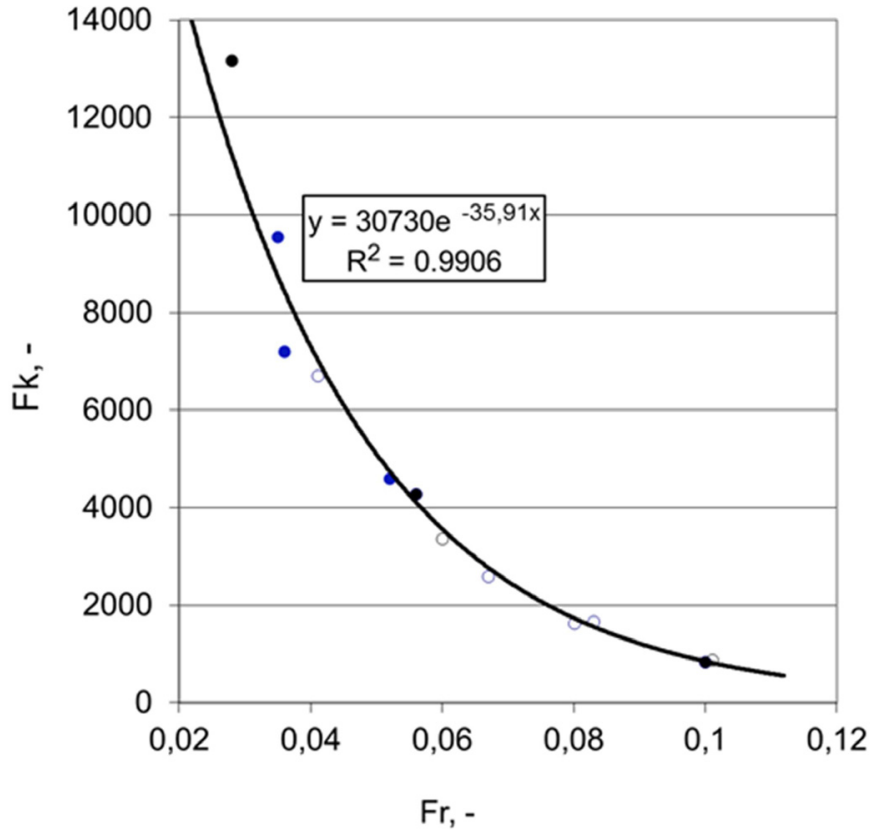

Fig. 5. Relations between Froude number $(F r)$ and additional pressure loss coefficient $(F k)$

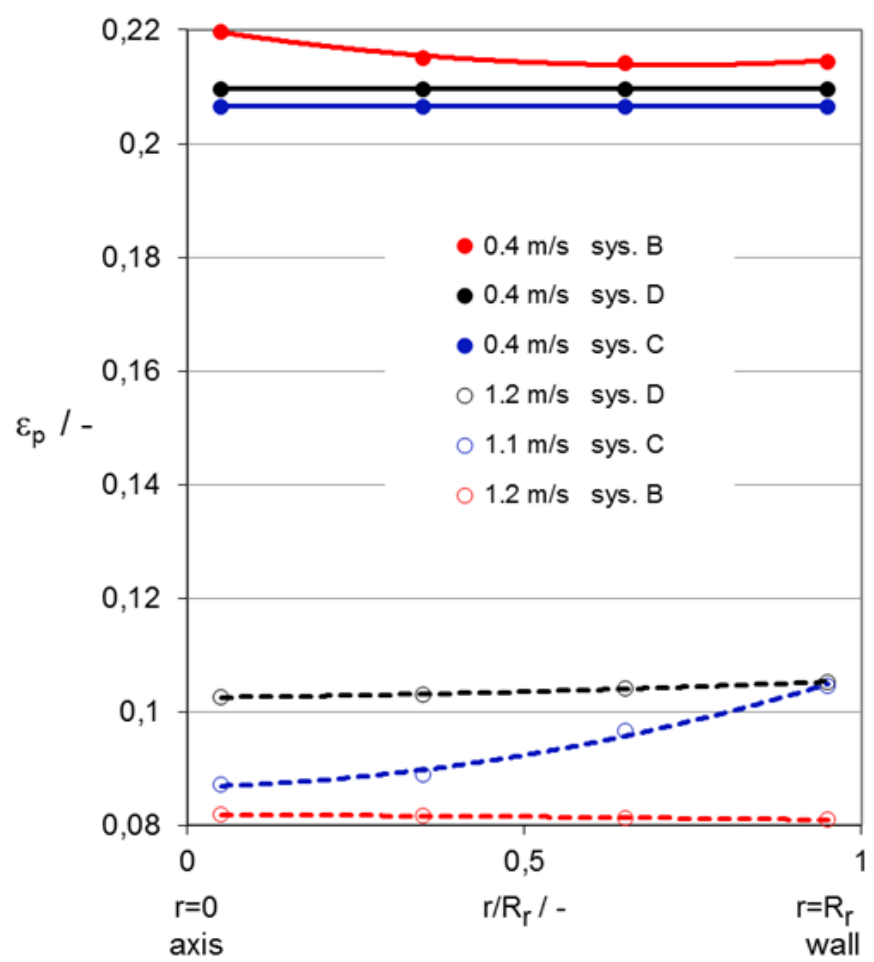

Fig. 6. Radial distribution of $\varepsilon_{p}$, coefficients at the lower section $(0-100 \mathrm{~mm})$ of a bed height

\section{Conclusion}

The model research on radial distribution of static pressure and radial distribution of powder were conducted during multiphase (gas-powder-moving bed) flow. Three standard metallurgical systems were tested: blast furnace sinter bed-coal powder (C system), blast furnace pellets bed-coal powder (D system) and blast furnace pellets bed-iron powder (B system). It was found that all analyzed systems feature high static pressure differentiations at almost identical values of initial indices of void spaces $\varepsilon_{0}$ (ranging from 0.48 to 0.49 ). Pronounced differences appear when B system is contrasted with $\mathrm{C}$ and D systems. In case of systems with coal powder close to the gas inlet (at the wall) the pressure is the highest. When the system contains iron powder the pressure increases from the walls towards bed axis. This diversity results from the fact that radial distribution of coal powder differs totally from radial distribution of iron powder. Coal particles are lighter than iron ones. They feature different surface properties. Thus the change of the type of powder particles affects the mechanism of powder holdup in the bed. Such change may result in excessive accumulation of powder in the packed bed of metallurgical shafts and cause serious problems leading to pressure increase and in consequence bed suspension. To prevent such negative course of events it is necessary to set the most important parameters which would decide about radial differentiations of powder holdup in the bed.

The studies are planned to be continued. In the stage which would follow radial distribution of static and dynamic fractions of coal powder held up in the packed bed will be investigated.

\section{Acknowledgements}

This work was supported by Polish Ministry for Science and Higher Education under internal grant BK264/RM2/2016 for Institute of Metals Technology, Silesian University of Technology, Poland.

\section{REFERENCES}

[1] R.C. Brown, H. Shi, G. Colver, S.-C. Soo, Powder Technology 138 (2-3), 201-210 (2003).

[2] L. Guan, Z. Gu, Z. Yuan, L. Yang, W. Zhong, Y. Wu, S. Sun, Fuel 163, 122-128 (2016).

[3] J. Xu, S.-L. Wu, Gulo, K.-P. Du, 6th International Congress on the Science and Technology of Ironmaking 2012, ICSTI 2012; Rio de Janeiro; Brazil; 14 October 2012 through 18 October 2012; Code 99237, 1, 414-424 (2012).

[4] H. Nogami, Y. Ueki, Yasuaki, T, Murakami, S. Uesda, Tetsu-To-Hagane Journal of the Iron and Steel Institute of Japan, 100 (2), 227-245 (2014).

[5] S. Kikuchi, T. Kon, S. Ueda, S. Natsui, R. Inoue, T. Ariyama, ISIJ International, 55 (6), 1313-1320 (2015).

[6] T. Merder, J. Pieprzyca, M. Warzecha, Metalurgija, 48 (3), $143-$ 146 (2009).

[7] M. Saternus, T. Merder, P. Warzecha, Solid State Phenomena, 176, 1-10 (2011)

[8] B. Wright, P. Zulli, Z.Y. Zhou, Powder Technology 208 (1), 86-90 (2011).

[9] S.-W. Du, Ch.-P. Yeh, W.-H. Chen, Ch.-H. Tsai, J. A. Lucas, Fuel 143, 98-106 (2015).

[10] B. Panic, Metalurgija, 52 (2), 177-180 (2013).

[11] B. Panic, Metalurgija, 50 (3), 183-187 (2011). 